\title{
Role of LXRs in control of lipogenesis
}

\author{
Joshua R. Schultz, ${ }^{1,3}$ Hua Tu, ${ }^{1,3}$ Alvin Luk, ${ }^{1}$ Joyce J. Repa, ${ }^{2}$ Julio C. Medina, ${ }^{1}$ Leping Li, ${ }^{1}$ \\ Susan Schwendner, ${ }^{1}$ Shelley Wang, ${ }^{1}$ Martin Thoolen, ${ }^{1}$ David J. Mangelsdorf, ${ }^{2}$ Kevin D. Lustig, ${ }^{1}$ \\ and Bei Shan ${ }^{1,4}$ \\ ${ }^{1}$ Tularik Inc., South San Francisco, California 94080, USA; ${ }^{2}$ Howard Hughes Medical Institute and Department \\ of Pharmacology, University of Texas Southwestern Medical Center, Dallas, Texas 75390, USA
}

\begin{abstract}
The discovery of oxysterols as the endogenous liver $\mathbf{X}$ receptor (LXR) ligands and subsequent gene targeting studies in mice provided strong evidence that LXR plays a central role in cholesterol metabolism. The identification here of a synthetic, nonsteroidal LXR-selective agonist series represented by T0314407 and T0901317 revealed a novel physiological role of LXR. Oral administration of T0901317 to mice and hamsters showed that LXR activated the coordinate expression of major fatty acid biosynthetic genes (lipogenesis) and increased plasma triglyceride and phospholipid levels in both species. Complementary studies in cell culture and animals suggested that the increase in plasma lipids occurs via LXR-mediated induction of the sterol regulatory element-binding protein 1 (SREBP-1) lipogenic program.
\end{abstract}

[Key Words: LXR; lipogenesis; SREBP; fatty acid; triglyceride]

Received September 13, 2000; revised version accepted October 2, 2000.

Liver X receptors (LXRs), LXR $\alpha$ (NR1H3), and LXR- $\beta$ (NR1H2), are nuclear receptors that regulate the metabolism of several important lipids, including cholesterol and bile acids. LXRs were first identified as orphan members of the nuclear receptor superfamily (Song et al. 1994; Willy et al. 1995). The identification of a specific class of oxidized derivatives of cholesterol as ligands for the LXRs, in combination with the description of an LXR response element in the promoter of the rat cholesterol $7 \alpha$-hydroxylase gene (CYP7A1), suggested that LXRs play an important role in the regulation of cholesterol homeostasis (Janowski et al. 1996, 1999; Lehmann et al. 1997). Additional support for this role came from the analysis of $\operatorname{LXR} \alpha$-deficient mice ( $\operatorname{LXR} \alpha-/-)$, which uncovered the dysregulation of the CYP7A1 gene and several other important lipid-associated genes (Peet et al. 1998). Studies utilizing these animals confirmed the essential function of LXR $\alpha$ as a major sensor of dietary cholesterol and an activator of the bile acid synthetic pathway in mice.

Three sterol regulatory element-binding proteins (SREBP-1a, -1c, and -2) stimulate transcription of a number of genes involved in the synthesis and receptor-mediated uptake of cholesterol and fatty acids (Brown and Goldstein 1997; Horton and Shimomura 1998). Results to date support the notion that SREBP-1 primarily activates the fatty acid, triglyceride, and phospholipid pathways, while SREBP-2 is the prominent isoform support-

\footnotetext{
${ }^{3}$ These authors contributed equally to this work.

${ }^{4}$ Corresponding author.

E-MAIL shan@tularik.com; FAX (650) 825-7400.

Article and publication are at www.genesdev.org/cgi/doi/10.1101/ gad.850400.
}

ing cholesterol synthesis and uptake (Shimano et al. 1996; Brown and Goldstein 1997; Horton and Simomura 1998; Horton et al. 1998). In fatty acid biosynthesis, proteases release nuclear SREBP-1c (the major SREBP-1 isoform in the liver of animals), which activates transcription of the major genes of fatty acid synthesis including acetyl CoA carboxylase (ACC), fatty acid synthase (FAS), stearoyl CoA desaturase-1 (SCD-1), glycerol-3-phosphate acyltransferase, and others (Bennett et al. 1995; Lopez et al. 1996; Ericsson et al. 1997; Shimomura et al. 1998).

In this study, we describe the identification and biochemical features of a nonsteroidal LXR agonist, T0314407, and its analog T0901317. Our understanding of the in vivo role of LXR in lipid metabolism was extended by induction of LXR-regulated pathways in mice and hamsters. We show that LXR agonist treatment induces the expression of genes associated with fatty acid biosynthesis, and it raises plasma triglyceride levels in these animal models. Administration of T0901317 to mice lacking both the LXR $\alpha$ and $\beta$ genes $(\operatorname{LXR} \alpha / \beta-/-)$ corroborated both the requirement of LXRs in the activation of lipogenesis and their being key components of the triglyceride response. We present data that are consistent with the hypertriglyceridemic effect being associated with LXR agonist-dependent induction of the SREBP-1 lipogenic program.

\section{Results}

On agonist binding, nuclear receptors undergo a conformational change that increases their affinity for coactivators. Recruitment of coactivator to agonist-bound nuclear receptor is a critical step in the formation of an 
active transcription complex on DNA. Studies have demonstrated that coactivator fragments containing the motif LXXLL, where $\mathrm{L}$ is leucine and $\mathrm{X}$ is any amino acid, bind to nuclear receptors in an agonist-dependent manner (Heery et al. 1997). In this study, we synthesized a short synthetic rhodamine-labeled peptide containing an LXXLL motif and used it to develop a fluorescence polarization assay for agonist binding to $\operatorname{LXR} \alpha$. In this homogeneous biochemical assay, the greater the extent of rhodamine-peptide binding to $\operatorname{LXR} \alpha$, the greater the extent of fluorescence polarization observed. Thus, addition of an endogenous LXR ligand, 24(S),25-epoxycholesterol $(24,25-\mathrm{EC})$, to a mixture of LXR $\alpha$ protein and rhodamine-peptide led to a dose-dependent increase in fluorescence polarization (Fig. 1B). The $\mathrm{EC}_{50}$ determined for 24,25 -EC of $300 \mathrm{nM}$ is in agreement with the $\mathrm{K}_{\mathrm{i}}$ determined by a direct ligand-binding assay (Jankowski et al. 1999|. Screening of $>300,000$ compounds using this peptide sensor assay led to the identification of T0314407 ( $N$-methyl- $N$-[4-(2,2,2-trifluoro-1-hydroxy-1-trifluoromethylethyl)-phenyl]-benzenesulfonamide) as an initial lead (Fig. 1A). A derivative of T0314407 with improved pharmacological properties, T0901317 (N-(2,2,2-trifluoroethyl)-N-[4-(2,2,2-trifluoro-1-hydroxy-1-trifluoromethylethyl)-phenyl]-benzenesulfonamide), was developed through structure-activity relationship studies (Fig. 1A). Both T0314407 and T0901317 showed similar efficacy to 24,25-EC but were significantly more potent and bound to $\mathrm{LXR} \alpha$ with $\mathrm{EC}_{50}$ values of 100 and $20 \mathrm{nM}$, respectively (Fig. 1B).

To provide further evidence that these compounds bind directly to $\mathrm{LXR} \alpha$, a scintillation proximity assay (SPA) was developed with radiolabeled T0314407 (Fig.
1C). Unlabeled T0314407 and T0901317 effectively competed for the binding of radiolabeled T0314407 to LXR $\alpha$ in the SPA with $\mathrm{IC}_{50}$ values of 100 and $20 \mathrm{nM}$, respectively. 24,25-EC also competed with the binding. These results demonstrated direct binding of the synthetic ligands to LXR $\alpha$ and suggested that both the synthetic and endogenous ligands bind at the same site on LXR $\alpha$. We next tested whether these compounds were able to activate the receptor in a reporter gene assay. HEK293 cells were transiently transfected with an expression plasmid for the human $\operatorname{LXR} \alpha$ and a reporter plasmid containing two copies of an LXR response element (Willy et al. 1995) and then treated with increasing concentrations of T0314407, T0901317, or 24,25-EC (Fig. 2A). Both synthetic ligands induced transcriptional activity of LXR $\alpha$ nearly eightfold with $\mathrm{EC}_{50}$ values of 100 and $20 \mathrm{nM}$, respectively. Consistent with the results obtained in the direct binding assays, T0314407 and T0901317 appeared significantly more active than the endogenous ligand, 24,25-EC, which displayed an $\mathrm{EC}_{50}$ value of $\sim 3 \mu \mathrm{M}$.

To determine the specificity of T0314407 and T0901317, a similar transient transfection assay was employed that used chimeric receptors between the yeast transcription factor Gal4 and the nuclear receptor ligandbinding domain (Fig. 2B). Transcriptional activation by T0314407 and T0901317 was selective to LXRs, as these compounds failed to enhance the activity of most other nuclear receptors examined. While T0314407 and T0901317 showed the highest activity against $\operatorname{LXR} \alpha$, transactivation was also noted for chimeric Gal4-LXR $\beta$ and, to a lesser extent, Gal4-PXR (pregnane X receptor). PXR, a nuclear receptor involved in the CYP3A-mediated metabolism of a diverse collection of xenobiotics, is
Figure 1. Biochemical characterization of LXR ligands T0314407 and T0901317. (A) Chemical structure of T0314407, T0901317, and radiolabeled T0314407. (B) Effect of different LXR $\alpha$ agonists on recruitment of an LXXLL-containing peptide to the LXR $\alpha$ ligand-binding domain. $(C)$ Scintillation proximity assay (SPA) data showing the competitive binding curves of $\left[{ }^{3} \mathrm{H}\right]-\mathrm{T} 0314407$ to $\mathrm{LXR} \alpha$ protein and the ability of unlabeled LXR ligands to displace $\left[{ }^{3} \mathrm{H}\right]-\mathrm{T} 0314407$.
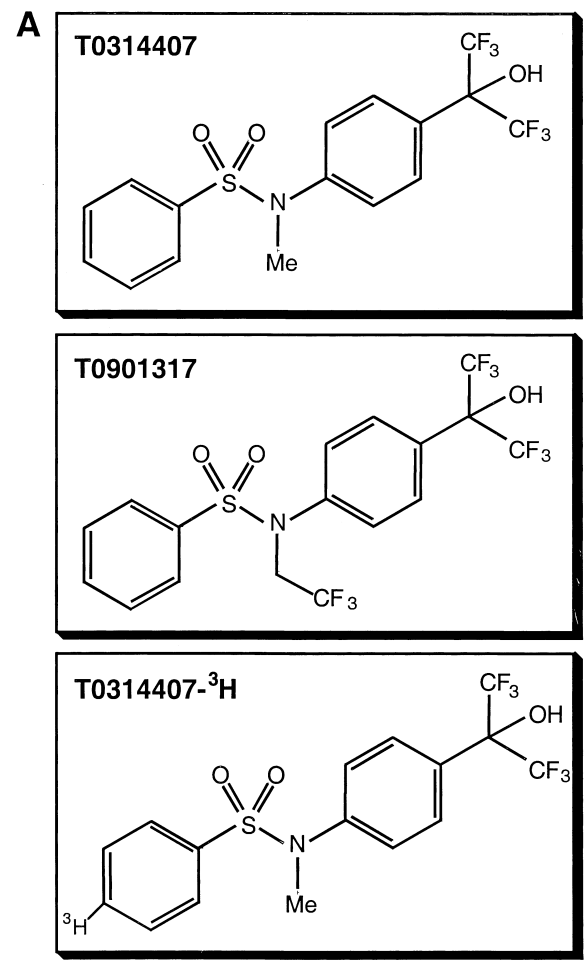

B

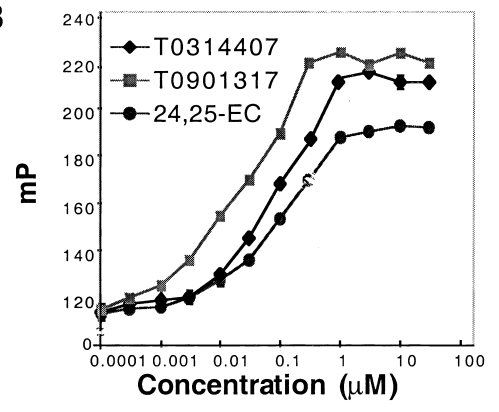

C

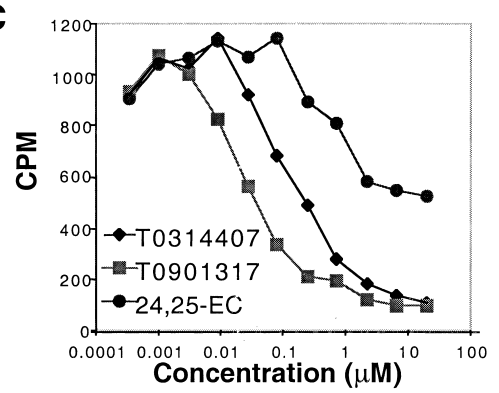


A
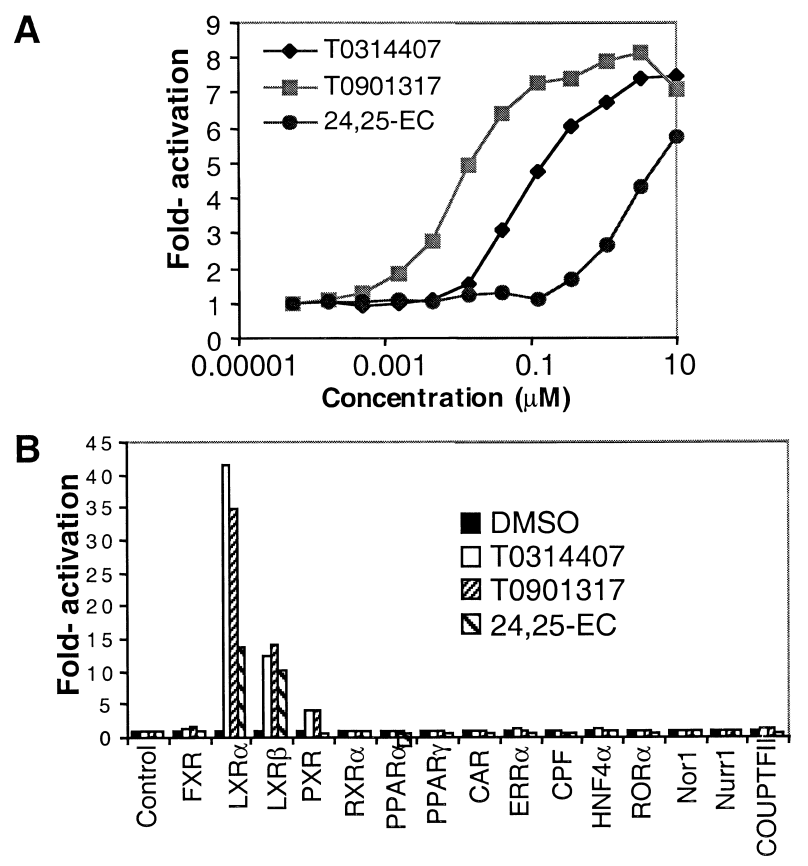

Figure 2. (A) Dose responses to LXR ligands in an HEK293 transient transfection assay using a wild-type LXR $\alpha$ expression plasmid and a luciferase reporter gene containing two copies of an LXR response element. DMSO treatments were used to derive the basal level of activation. $(B)$ Specificity of LXR activation by LXR ligands in a transient transfection assay. HEK293 cells were cotransfected with a luciferase reporter gene containing four copies of the Gal4 DNA-binding site and the various chimeric Gal4 (DNA-binding domain)-nuclear receptor (ligandbinding domain) proteins shown. Cells were treated with the indicated compounds at concentrations of $1 \mu \mathrm{M}, 5 \mu \mathrm{M}$, and 10 $\mu \mathrm{M}$ for T0901317, T0314407, and 24,25-EC, respectively.

known to be activated by a large number of synthetic compounds (Jones et al. 2000).

Our in vitro characterization established T0901317 as a highly potent and selective nonsteroidal LXR $\alpha$ ligand. To determine the compound's effects on plasma lipid homeostasis, T0901317 was evaluated in small-animal models. Oral treatment of C57BL/6 mice with T0901317 resulted in significant elevations of plasma triglycerides (Fig. 3A). Increases in plasma very low density lipoproteins (VLDL) triglycerides occurred with comparable increases in plasma total cholesterol (mainly high-density lipoproteins [HDL] cholesterol; Fig. 3B) and HDL-phospholipid. In contrast to humans, which use low-density lipoproteins (LDL) for the transport of most plasma cholesterol, mice carry a preponderance of their cholesterol on HDL. Accordingly, T0901317 was also tested in hamsters, which have lipoprotein cholesterol distributions that more closely resemble human profiles. Similar increases in plasma triglycerides were quantified in the hamster (Fig. 3C). Separation of plasma lipoproteins by fast protein liquid chromatography (FPLC) in combination with analysis of the lipid content across the FPLC fractions further established the increase in triglycerides and demonstrated a principal expansion of the VLDL fraction in mice and hamsters (Fig. 3C).
To understand the mechanism whereby LXR agonist increased plasma triglycerides, changes in global gene expression in response to LXR agonist treatment were assessed by gene expression micrarrays (GEM) and Northern blot analysis. The GEM experiments were carried out using RNA derived from control and LXR agonist-treated HepG2 cells and mice. T0901317 significantly modulated the expression of a small number of genes in both cell culture and the mouse. Among the genes that showed up-regulation, significant induction was noted for fatty acid synthase and SREBP-1 (greater
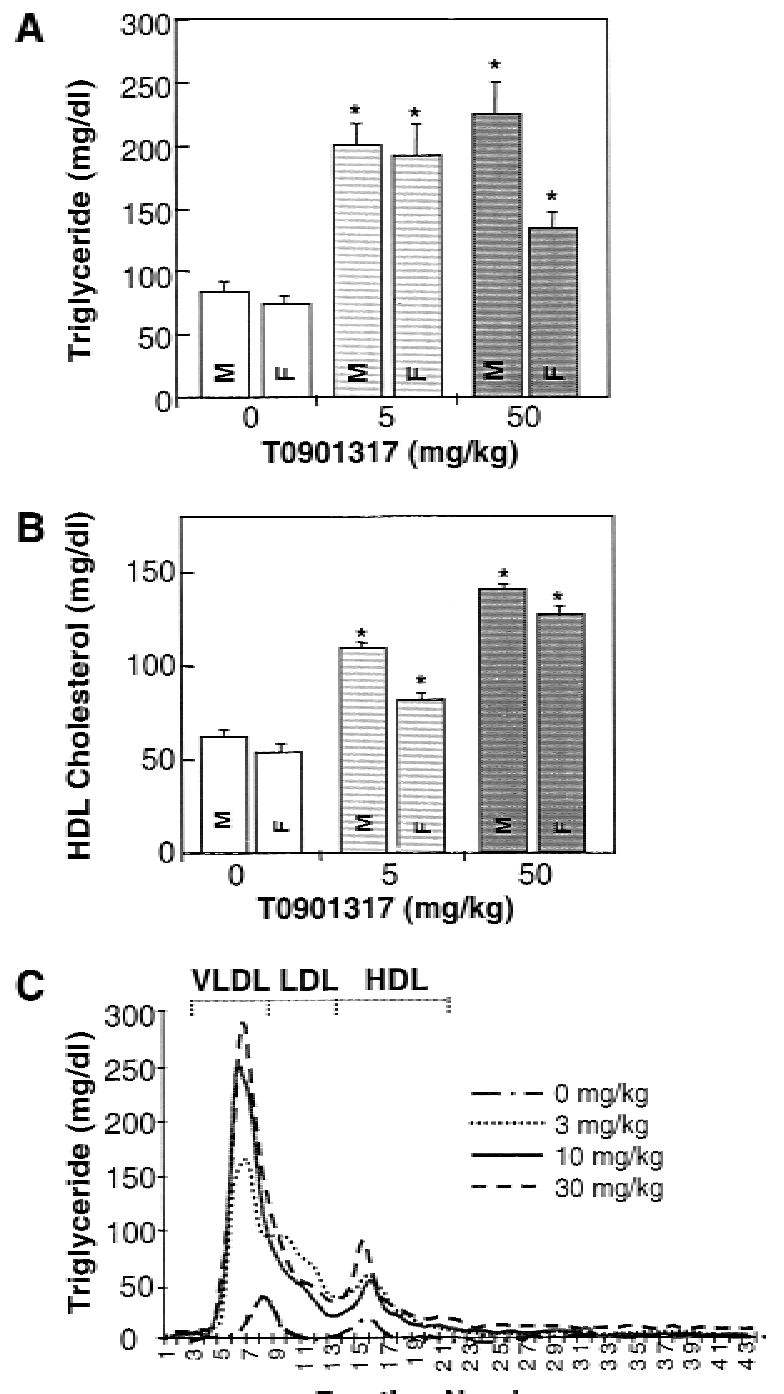

Fraction Number

Figure 3. Plasma lipid levels in animals treated with LXR agonist T0901317. The concentrations of $(A)$ plasma triglycerides and $(B)$ HDL-cholesterol for C57BL/ 6 mice $(n=5$, for each treatment group; M, males; F, females). (C) Separation of Golden Syrian hamster plasma by fast protein liquid chromatography (FPLC) in combination with analysis of the triglyceride content across FPLC fractions. Lipid data are reported as the mean \pm SD for the number of determinations (animals) described in each experiment. Statistical significance (kybd) was defined as $P<0.05$ (ANOVA using SAS programming statistical test for controls and LXR agonist-treated animals). 
Schultz et al.

than a twofold increases). In addition, a prominent subset of $>20$ fatty acid metabolism-associated genes was increased by LXR agonist. This subset included fatty acid synthase, carnitine palmitoyltransferase 1, acyl-CoAbinding protein, acyl glycerol-3-phosphate acyltransferase, fatty acid amide hydrolase, acyl carrier protein, fatty acid binding and transport proteins, and colipase, a small protein cofactor required by lipase for the efficient hydrolysis of dietary lipid. Up-regulation of liver and intestinal phosphoethanolamine cytidylyltransferase, a key regulatory enzyme in the CDP-ethanolamine pathway for phosphatidylethanolamine synthesis, was also noted. Additional characterization of gene expression was performed by Northern blot analysis using RNA isolated from mice and hamsters (Fig. 4). In the mouse, increases in hepatic fatty acid biosynthetic gene activity were noted after treatment with T0901317, including ACC (twofold), FAS (threefold) and SCD-1 (up to ninefold; Fig. $4 A, B)$. The induction of fatty acid biosynthetic gene activity by T0901317 is consistent (though diametrically opposed) with the reduction in expression of a similar subset of genes in LXR $\alpha$-null mice (Peet et al. 1998). Steady-state mRNA levels of CYP7A1, SCD-1, and SREBP-1 increased in a dose-dependent manner (Fig. 4B). In contrast, the transcript levels of genes associated with cholesterol biosynthesis such as squalene synthase (SQS)
A

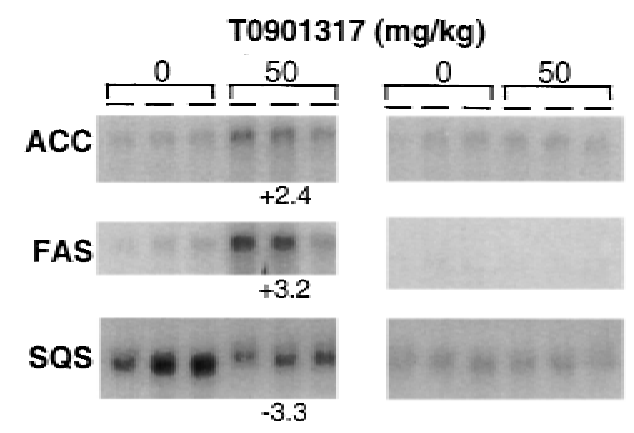

HMG COA S

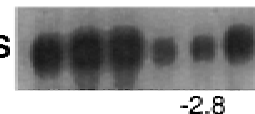

$-2.8$
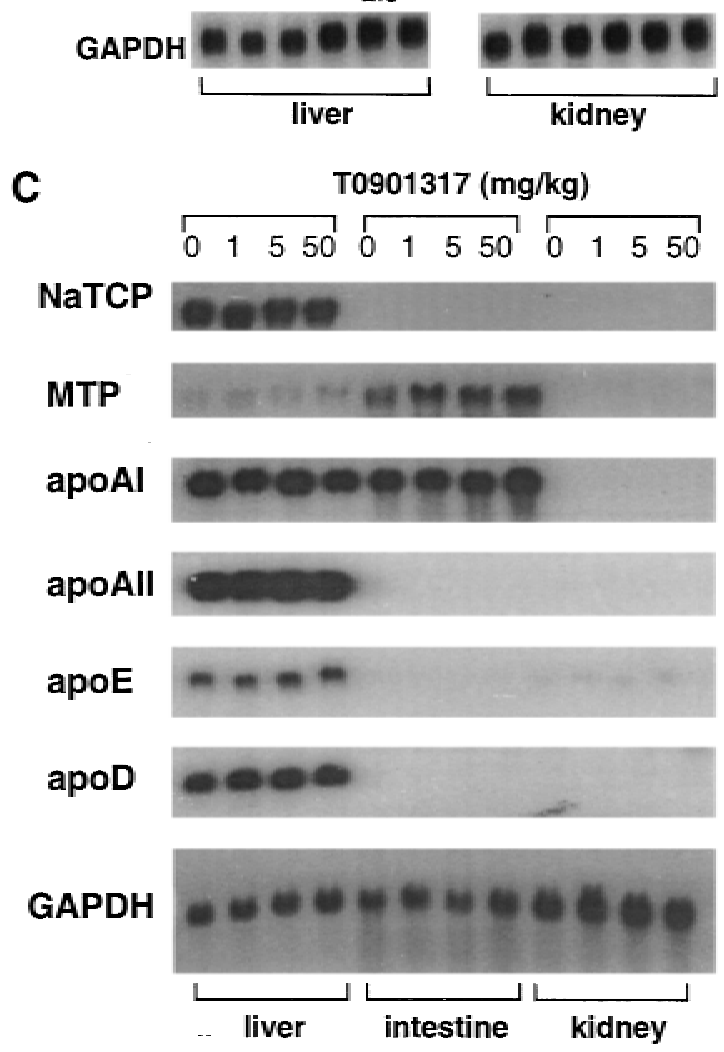

B

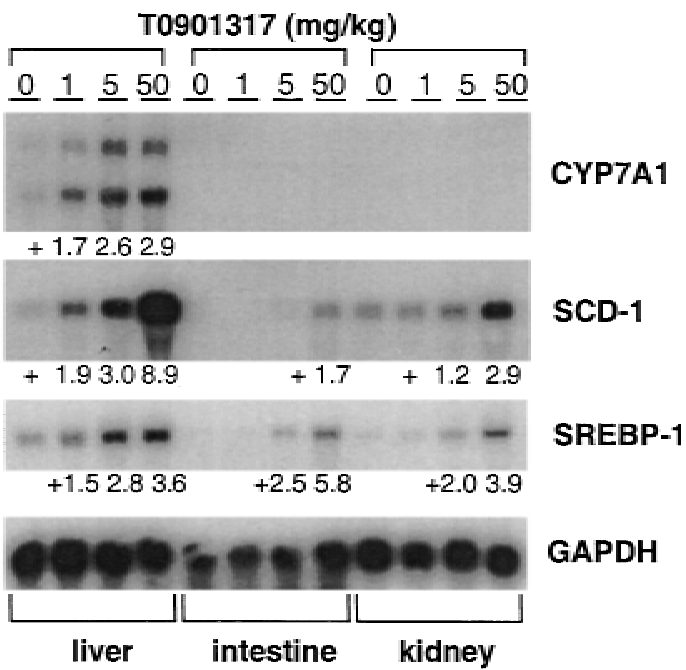

D

T0901317 (mg/kg)

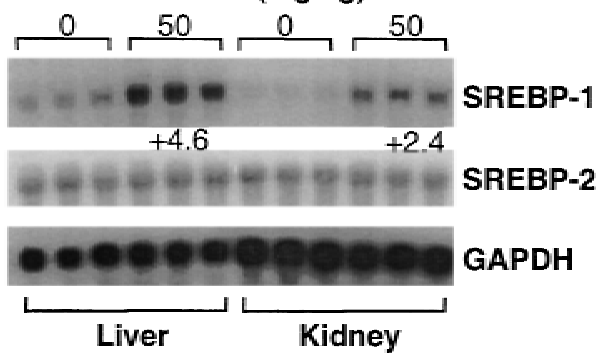

$\mathbf{E}$ T0314407 ( $\mu \mathrm{M})$

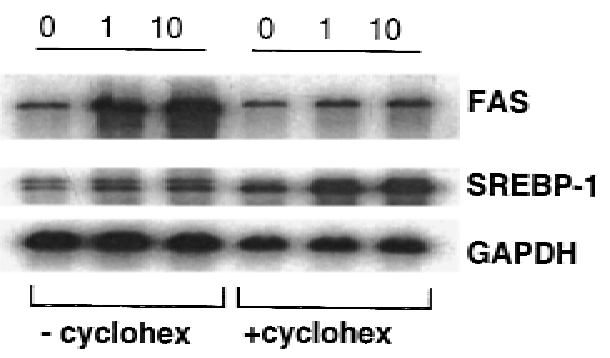

Figure 4. Northern blot analysis. Total RNA was isolated from the tissues indicated from mice $(A, B, C)$ and hamsters $(D)$. The numerical data shown with each figure represents the fold increase $(+)$ or decrease $(-)$ of expression relative to corresponding vehicletreated controls. (E) HepG2 cells were incubated in culture media with or without cycloheximide (cyclohex). 
and 3-hydroxy-3-methylglutaryl coenzyme A synthase (HMG CoA S) were consistently reduced after treatment with T0901317 (Fig. 4A). A subset of genes associated with lipid metabolism remained unaffected by LXR agonist treatment, including apolipoprotein (apo)AI, apoAII, apoD, apoE, microsomal triglyceride transport protein (MTP), and sodium taurocholate cotransporter (NaTCP; Fig. 4C). Other transcripts that also did not appear to vary in level included the scavenger receptor-BI (SR-BI), apoCIII, and acyl CoA:diacylglycerol transferase (DGAT; data not shown).

As described above, increased fatty acid biosynthetic gene activity was accompanied by increases in hepatic SREBP-1 steady-state mRNA levels (approximately twoto fivefold). In comparison to the relatively high induced levels of SREBP-1, the amount of SREBP-2 mRNA remained unchanged after LXR agonist treatment (Fig. 4D). To determine if LXR directly modulates SREBP-1 gene expression, or if target gene activation requires de novo protein synthesis, a series of Northern blots were carried out using RNA prepared from T0314407-dosed HepG2 cells treated both with and without cycloheximide, an inhibitor of protein synthesis (Fig. 4E). We found that, while cycloheximide arrested the agonist-mediated increase in levels of FAS mRNA, induction of SREBP-1 gene expression persisted. This outcome suggests that the effect of LXR agonist on SREBP-1 is a primary and direct consequence of LXR agonist-activated transcription. In contrast, activation of FAS and other downstream SREBP-1 targets is likely to be secondary to the stimulation by SREBP-1.

To further validate the T0901317-mediated lipid changes and gene regulation, $\operatorname{LXR} \alpha / \beta-/-$ mice were ad- ministered with the LXR agonist, and plasma and hepatic triglyceride levels were quantified. FPLC and lipid measurements showed that T0901317-treated mice (wild type) had an approximate threefold increase in plasma VLDL-triglyceride (Fig. 5A), in comparable agreement with the increase in total plasma triglycerides measured in control and T0901317-treated (wild-type) mice $(82.7 \pm 9.5 \mathrm{mg} / \mathrm{dL}$ and $225.7 \pm 7 \mathrm{mg} / \mathrm{dL}$, respectively). The baseline VLDL-triglyceride level in $\operatorname{LXR} \alpha /$ $\beta-/-$ mice was significantly reduced (approximately fourfold) compared to control mice. LXR agonist treatment of the $\operatorname{LXR} \alpha / \beta-/-$ mice only led to a relatively minute increase in plasma VLDL-triglyceride. This result was in agreement with total plasma triglyceride measurements, which also showed only scant increases in T0901317-treated LXR $\alpha / \beta-/$ - mice compared with vehicle-treated LXR $\alpha / \beta-/-$ animals. HDL-phospholipid profiles were also LXR-dependent, and similar to those described for VLDL triglyceride (Fig. 5B). Analysis of hepatic triglyceride levels showed a significant fivefold elevation of hepatic triglyceride in wild-type mice compared to vehicle-treated controls (Fig. 5C). Hepatic triglyceride levels were significantly lower in LXR $\alpha / \beta-/-$ mice, and no significant elevation resulted from treatment with T0901317. The lack of regulation of the SREBP-1, SCD-1, FAS, or ACC gene in response to LXR agonist in the deficient mice was also consistent with the plasma and hepatic lipid characterization (Fig. 5D). Thus, compared to the robust response of wild-type mice, administration of LXR agonist T0901317 to LXRnull mice had little or no effect on either the lipid profile or the expression of genes involved in lipid metabolism. These results clearly demonstrated that the lipid
A

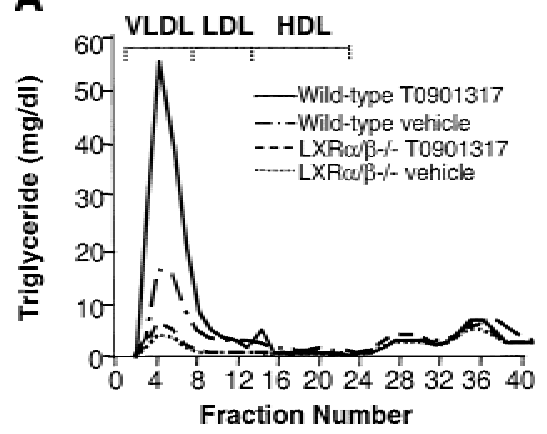

B

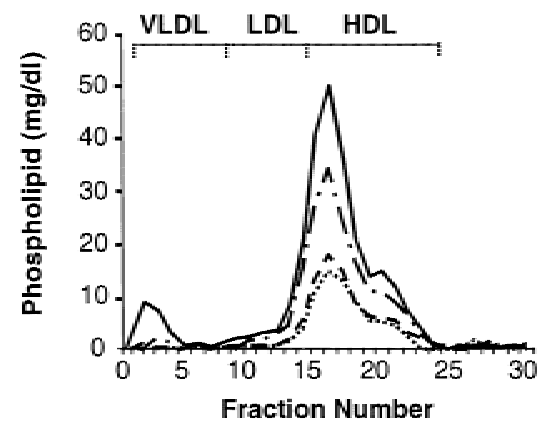

C

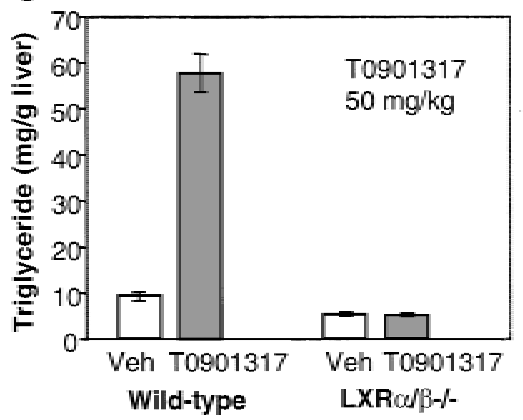

D T0901317 (50 $\mathrm{mg} / \mathrm{kg})$

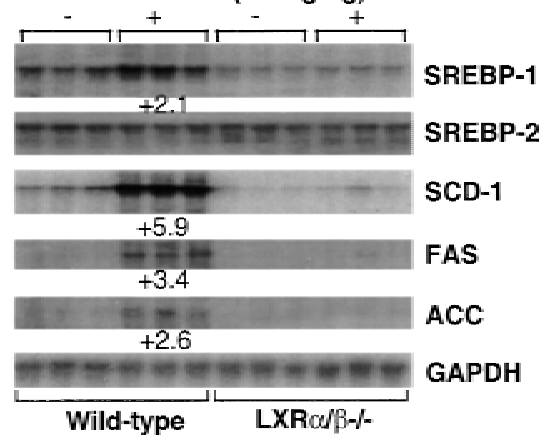

Figure 5. Agonist T0901317-mediated increases in hepatic and plasma triglyceride levels and lipogenic mRNA requires LXRs. Analysis of the lipid content of livers and plasma from vehicle- and T0901317-treated wild-type and LXR $\alpha / \beta-/$ - mice $(n=5$ for each of the four groups shown, treatment for $7 \mathrm{~d}$ ). Pooled plasma (50 $\mu \mathrm{L}$ from each of five mice per group) was fractionated and lipids analyzed as described. Shown are the concentrations for $(A)$ FPLC triglyceride, $(B)$ FPLC phospholipid, and $(C)$ hepatic triglyceride. $(D)$ Northern blot analysis of hepatic SREBP-1, SREBP-2, SCD-1, FAS, and ACC mRNA levels. 
changes mediated by the synthetic LXR agonist were indeed LXR-dependent.

Our current understanding of the control of cholesterol and fatty acid biosynthesis has largely been ascribed to posttranscriptional events associated with the regulation of SREBP processing (Brown and Goldstein 1997; Horton and Shimomura 1998). The current studies suggest an additional primary level of transcriptional regulation that is also available to the cell, one controlled by LXR-mediated induction of SREBP-1 and its associated downstream lipogenic program. Our results support a mechanism whereby LXR directly activates SREBP-1 gene transcription, presumably through an LXR response element (LXRE), and where subsequent activation of lipogenic genes such as FAS, ACC, and SCD-1 occurs secondary to SREBP-1 gene activation. Indeed, control of SREBP-1 gene expression through an LXRE has recently been established and RNase protection assays revealed induction of the SREBP-1c isoform by LXR agonist (Repa et al. 2000a). Functional LXREs have also been shown to exist in a number of genes associated with cholesterol metabolism, including the rate-limiting enzyme in the classical bile acid biosynthetic pathway CYP7A1 (Lehmann et al. 1997), cholesterol ester transferase protein (CETP; Luo and Tall 2000) and the ATP binding cassette $(\mathrm{ABC})$ transporter, $\mathrm{ABCA} 1$ (Costet et al. 2000) gene promoters. The oxysterol-mediated induction of human white (murine $\mathrm{ABC} 8$ ) gene expression also appears to be mediated by LXRs (Venkateswaran et al. 2000). In addition, concurrent with this report, Repa et al. (2000b) have also used T0901317 and LXR $\alpha / \beta-/-$ mice to show the requirement of LXRs in ABCA1 gene expression and the involvement of active reverse cholesterol transport as a determinant of intestinal cholesterol absorption. Our studies support an expanded role for LXRs as important regulators of bile acid synthesis, reverse cholesterol transport from peripheral tissues, intestinal cholesterol absorption, and triglyceride and phospholipid metabolism.

The LXR agonists described in this study do not activate SREBP-2 or its downstream targets. This observation is consistent with the previously noted independent regulation of SREBP-1 and -2 in hamster liver (Sheng et al. 1995). Furthermore, consistent with the observations in LXR $\alpha-/$ - mice (Peet et al. 1998), LXR agonist treatment resulted in a reduction of cholesterol biosynthetic gene mRNA levels. Collectively, these observations provide additional support for distinct and uncoupled SREBP-1 and SREBP-2 regulation of fatty acid and cholesterol biosynthetic pathways.

In contrast to LXR $\alpha-/-$ mice, LXR $\beta-/-$ mice do not show any obvious lipid phenotype in response to cholesterol feeding (D.J. Mangelsdorf, unpubl.). Accordingly, it has been hypothesized that LXR $\alpha$ is capable of compensating for LXR $\beta$ (in LXR $\beta$-null mice). In vitro, both LXR $\alpha$ and LXR $\beta$ are able to up-regulate cholesterol metabolism-associated genes such as human CETP and ABCA1 (Luo and Tall 2000; Costet et al. 2000). This redundancy may, at least in part, explain compensatory activity of $\operatorname{LXR} \alpha$ in the LXR $\beta$-null mouse. In contrast, LXR $\beta$ is clearly unable to compensate for the lack of LXR $\alpha$ (Peet 1998). This lack of compensation suggests that, ultimately, $\mathrm{LXR} \alpha$ and $\mathrm{LXR} \beta$ have at least some distinct primary targets in vivo. The LXR agonists described herein have been shown to be selective for LXRs over numerous other nuclear receptors. However, it should be noted that these compounds do not exhibit specificity with regard to $\operatorname{LXR} \alpha$ versus $\mathrm{LXR} \beta$. This indiscriminant behavior may explain why normalization of the lipid phenotype associated with LXR agonist administration in this study could only be achieved by treatment of doubly deficient $\mathrm{LXR} \alpha / \beta-/-$ mice and not with $\operatorname{LXR} \alpha-/-$ mice (data not shown).

Hypertriglyceridemia results from numerous conditions including genetic defects in lipoprotein lipase and apolipoproteins CII, CIII, and E (Ghiselli et al. 1982; Ito et al. 1990; Parrot et al. 1992; Benlian et al. 1996) and is a hallmark of a diverse range of disorders including diabetes mellitus, hypothyroidism, nephrotic syndromes, lipodystrophies (Chait and Brunzell 1990), and HIV-positive individuals undergoing treatment with protease inhibitors (Sullivan et al. 1998). Increasing evidence supports an independent role of hypertriglyceridemia in cardiovascular disease for both men and women in the general population and a significant clinical benefit from decreasing triglyceride levels (Hokanson and Austin 1996; Brewer 1999; Hodis et al. 1999; Rubins et al. 1999; Austin et al. 2000). These observations support the need for a better understanding of the molecular determinants that control fatty acid metabolism and plasma triglyceride levels as well as the development of effective pharmacological agents that selectively reduce this risk factor. The results presented here highlight the feasibility of utilizing LXR agonists to further identify key factors that link lipogenesis to triglyceride synthesis, hepatic VLDL assembly, and secretion. These studies also raise the intriguing possibility that selective and specific LXR $\alpha$ antagonists may serve as potentially useful therapeutics to oppose hypertriglyceridemia and reduce cardiovascular disease.

\section{Materials and methods}

Peptide sensor assay

The LXR $\alpha$ ligand-binding domain was fused to the C-terminus of glutathione S-transferase (GST) and the resultant GST-LXR protein was expressed in Escherichia coli and purified on glutathione beads. Rhodamine-labeled peptide (10 nM; with amino acid sequence ILRKLLQE) was incubated on a shaker for $1 \mathrm{~h}$ with $400 \mathrm{nM}$ GST-LXR and the indicated compounds in $100 \mu \mathrm{L}$ of buffer (10 mM Hepes, $150 \mathrm{mM} \mathrm{NaCl}, 2 \mathrm{mM} \mathrm{MgCl}$, $5 \mathrm{mM}$ DTT at $\mathrm{pH}$ 7.9) in a 96-well plate. Fluorescence polarization $(\mathrm{mP})$ was measured on an LJL analyst (LJL Biosystems).

Reporter gene assay

HEK293 cells were cotransfected with a luciferase reporter gene and the various Gal4-nuclear receptor chimeric constructs shown and a $\beta$-galactosidase ( $\beta$-gal) expression vector for normalization. Transfected cells were treated with the indicated compounds for $20 \mathrm{~h}$ before being harvested. Transfection data and luciferase results are normalized to $\beta$-gal and expressed as the fold-induction relative to DMSO controls. 


\section{Plasma lipid analysis}

C57BL/6 mice (Charles River Laboratories) were between 6 and 10 wk old and weighed $20-30 \mathrm{~g}$ at the initiation of treatment. Golden Syrian Hamsters (Harlan Sprague-Dawley) were between 12 and 16 wk old (80-150 g). Animals were fed regular chow diets containing $\sim 4 \%$ fat and $0.02 \%$ cholesterol (PMI Picolab 5053 Chow). LXR $\alpha$ and $\beta-/-$ mice were reared at the University of Texas Southwestern (UTSW) Medical Center at Dallas in accordance with the Institutional Animal Care and Research Advisory Committee at the UTSW Medical Center. Mice at UTSW were maintained on a $12 \mathrm{~h}$ light $/ 12 \mathrm{~h}$ dark cycle and fed ad libitum a cereal-based mouse chow diet (No. 7001, Harlan Teklad).

Plasma was prepared from euthanized mice using standard centrifugation techniques and analyzed for plasma total cholesterol, HDL cholesterol, and triglyceride concentrations using a Hitachi 704 Clinical Analyzer. FPLC of plasma lipoproteins was accomplished using $200 \mu \mathrm{L}$ aliquots of pooled plasma (from three to five animals) and fractionated on Superose 6 columns (Pharmacia). Cholesterol, triglyceride, and phospholipid concentrations in the fractions were determined enzymatically with reagents from Boehringer, Sigma, and Wako, respectively. Hepatic lipids were extracted and analyzed for triglyceride essentially as described (Bucolo and David 1973; Yokonde et al. 1990).

\section{Gene expression}

Total RNA extraction and purification for Northern blot analysis was accomplished using the TRI reagent (Molecular Research Center). For GEM analysis, mice were treated for $7 \mathrm{~d}$ with and without T0901317 (5 mg/kg) p.o. Total RNA from liver, small intestine (jejunum), and kidney of control $(n=3)$ and agonist-treated animals $(n=3)$ was isolated, pooled, subjected to two rounds of oligo $d(T)$ cellulose chromatography, converted into cDNA, and hybridized to Incyte's mouse GEM1 microarrays containing $\sim 8000$ IMAGE cDNA clones (http://www.incyte. com/reagents/catalog.jsp?page=gem/products/mousegem 1 ).

Mouse gene expression was assessed by Northern blot analysis using random primed, ${ }^{32} \mathrm{P}$-labeled, cDNA probes that were generated using the primers described in Supplementary Table I. Hybridization signals were quantified using a phosphoimager (Molecular Dynamics) and standardized against GAPDH controls. Mouse cDNA probes for the numerous genes analyzed were prepared using primers from mouse liver or intestinal cDNA as template. The SREBP-2 cDNA was a gift from J.D. Horton (University of Texas Southwestern Medical Center, Dallas); mouse and hamster CYP7A1 cDNAs were generously supplied by D.W. Russell (University of Texas Southwestern Medical Center, Dallas). SCD-1 was a gift from J. Ntambi (University of Wisconsin, Madison), and apoD was kindly provided by $\mathrm{E}$. Rassart (University of Quebec, Montreal).

For the Northern blot analysis from cycloheximide-treated HepG2 cells, tissue cultures were incubated in cell culture media with $10 \%$ lipid-deficient serum with or without $50 \mu \mathrm{g} / \mathrm{mL}$ cycloheximide. T0314407 was added after $30 \mathrm{~min}$ of cycloheximide treatment, cells were harvested $18 \mathrm{~h}$ later, and total RNA was extracted as described.

\section{Acknowledgments}

We thank Matthew Wright for pharmacological evaluations of LXR agonists; Gene Cutler for bioinformatics associated with GEM data mining; Miki Rich for DNA sequencing; Heather DiMaio and Susan Shetterly for excellent technical assistance;
Ronald Krauss and Patricia Blanche and the Donner Lipoprotein Analysis Core Laboratory, E.O. Lawrence National Laboratory, and University of California, Berkeley, for expert lipid analysis; and Jurgen Lehmann, Tim Hoey, Margrit Schwarz, Terry Rosen, David W. Russell, Steven L. McKnight, Michael S. Brown, and Joseph L. Goldstein, for critical reviews. D.J.M. is funded by the Howard Hughes Medical Institute, the Robert A. Welch Foundation, and the Human Frontier Science Program.

The publication costs of this article were defrayed in part by payment of page charges. This article must therefore be hereby marked "advertisement" in accordance with 18 USC section 1734 solely to indicate this fact.

\section{References}

Austin, M.A., McKnight, B., Edwards, K.L., Bradley, C.M., McNeely, M.J., Psaty, B.M., Brunzell, J.D., and Motulsky, A.G. 2000. Cardiovascular disease mortality in familial forms of hypertriglyceridemia: A 20-year prospective study. Circulation 101: 2777-2782.

Benlian, P., De Gennes, J.L., Foubert, L., Zhang, H., Gagne, S.E., and Hayden, M. 1996. Premature atherosclerosis in patients with familial chylomicronemia caused by mutations in the lipoprotein lipase gene. N. Engl. J. Med. 335: 848-854.

Bennett, M.K., Lopez, J.M., Sanchez, H.B., and Osborne, T.E. 1995. Sterol regulation of fatty acid synthase promoter: Coordinate feedback regulation of two major lipid pathways. $J$. Biol. Chem. 270: 25578-25583.

Brewer Jr., H.B. 1999. Hypertriglyceridemia: Changes in the plasma lipoproteins associated with an increased risk of cardiovascular disease. Am. J. Cardiol. 83: 3F-12F.

Brown, M.S. and Goldstein, J.L. 1997. The SREBP pathway: Regulation of cholesterol metabolism by proteolysis of a membrane-bound transcription factor. Cell 89: 331-340.

Bucolo, G. and David, H. 1973. Quantitative determination of serum triglycerides by the use of enzymes. Clin. Chem. 19: 476-482.

Chait, A. and Brunzell, J.D. 1990. Acquired hyperlipidemia (secondary dyslipoproteinemias). Endocrinol. Metab. Clin. N. Am. 19: 259-278.

Costet, P., Luo, Y., Wang, N., Tall, A.R. 2000. Sterol-dependent Transactivation of the ABC1 Promoter by the Liver X Receptor/Retinoid X Receptor. J. Biol. Chem. 275: 2824028245.

Ericsson, J., Jackson, S.M., Kim, J.B., Spiegelman, B.M., and Edwards, P.A. 1997. Identification of glycerol-3-phosphate acyltransferase as an adipocyte determination and differentiation factor $1-$ and sterol regulatory element-binding proteinresponsive gene. J. Biol. Chem. 272: 7298-7305.

Ghiselli, G., Schaefer, E.J., Zech, L.A., Gregg, R.E., and Brewer Jr., H.B. 1982. Familial apolipoprotein E deficiency. J. Clin. Investig. 70: 474-477.

Heery, D.M., Kalkhoven, E., Hoare, S., and Parker, M.G. 1997. A signature motif in transcriptional co-activators mediates binding to nuclear receptors. Nature 387: 733-736.

Hodis, H.N., Mack, W.J., Krauss, R.M., and Alaupovic, P. 1999. Pathophysiology of triglyceride-rich lipoproteins in atherothrombosis: Clinical aspects. Clin. Cardiol. 22: 15-20.

Hokanson, J.E. and Austin, M.A. 1996. Plasma triglyceride level is a risk factor for cardiovascular independent of high-density lipoprotein cholesterol level: A meta-analysis of population-based prospective studies. J. Cardiovasc. Risk 3: 213219.

Horton, J.D. and Shimomura, I. 1999. Sterol regulatory elementbinding proteins: Activators of cholesterol and fatty acid bio- 
synthesis. Curr. Opin. Lipidol. 10: 143-150.

Horton, J.D., Shimomura, I., Brown, M.S., Hammer, R.E., Goldstein, J.L., and Shimano, H. 1998. Activation of cholesterol synthesis in preference to fatty acid synthesis in liver and adipose tissue of transgenic mice overproducing sterol regulatory element-binding protein-2. J. Clin. Investig. 101: 2331-2339.

Ito, Y., Azrolan, N., O'Connell, A., Walsh, A., and Breslow, J.L. 1990. Hypertriglyceridemia as a result of human apo CIII gene expression in transgenic mice. Science 249: 790-793.

Janowski, B.A., Grogan, M.J., Jones, S.A., Wisely, G.B., Kliewer, S.A., Corey, E.J., and Mangelsdorf, D.J. 1999. Structural requirements of ligands for the oxysterol liver $\mathrm{X}$ receptors LXR $\alpha$ and LXR $\beta$. Proc. Nat1. Acad. Sci. 96: 266-271.

Janowski, B.A., Willy, P.J., Devi, T.R., Falck, J.R., and Mangelsdorf, D.J. 1996. An oxysterol signalling pathway mediated by the nuclear receptor LXR alpha. Nature 383: 728731.

Jones, S.A., Moore, L.B., Shenk, J.L., Wisely, G.B., Hamilton, G.A., McKee, D.D., Tomkinson, N.C., LeCluyse, E.L., Lambert, M.H., Willson, T.M., et al. 2000. The pregnane X receptor: A promiscuous xenobiotic receptor that has diverged during evolution. Mol. Endocrinol. 14: 27-39.

Lehmann, J.M., Kliewer, S.A., Moore, L.B., Smith-Oliver, T.A., Oliver, B.B., Su, J.L., Sundseth, S.S., Winegar, D.A., Blanchard, D.E., Spencer, T.A., et al. 1997. Activation of the nuclear receptor LXR by oxysterols defines a new hormone response pathway. J. Biol. Chem. 272: 3137-3140.

Lopez, J.M., Bennett, M.K., Sanchez, H.B., Rosenfeld, J.M., and Osborne, T.E. 1996. Sterol regulation of acetyl coenzyme A carboxylase: A mechanism for coordinate control of cellular lipid. Proc. Natl. Acad. Sci. 93: 1049-1053.

Luo, Y. and Tall, A.R. 2000. Sterol upregulation of human CETP expression in vitro and in transgenic mice by an LXR element. J. Clin. Investig. 105: 513-520.

Parrott, C.L., Alsayed, N., Rebourcet, R., and Santamarina-Fojo, S. 1992. ApoC-IIParis2: A premature termination mutation in the signal peptide of apoC-II resulting in the familial chylomicronemia syndrome. J. Lipid Res. 33: 361-367.

Peet, D.J., Turley, S.D., Ma, W., Janowski, B.A., Lobaccaro, J.M., Hammer, R.E., and Mangelsdorf, D.J. 1998. Cholesterol and bile acid metabolism are impaired in mice lacking the nuclear oxysterol receptor LXR $\alpha$. Cell 93: 693-704.

Repa, J.J., Liang, G., Ou, J., Bashmakov, Y., Lobaccaro, J.-M.A., Shimomura, I., Shan, B., Brown, M.S., Goldstein, J.L., and Mangelsdorf, D.J. 2000a. Regulation of mouse sterol regulatory element-binding protein-1c gene (SREBP-1c) by oxysterol receptors, LXR $\alpha$ and LXR $\beta$. Genes \& Dev. 14: 28192830.

Repa, J.J., Turley, S.D., Lobaccaro, J.A., Medina, J., Li, L., Lustig, K., Shan, B., Heyman, R.A., Dietschy, J.M., and Mangelsdorf, D.J. 2000b. Regulation of absorption and ABC1-mediated efflux of cholesterol by RXR heterodimers. Science 289: 1524 1529.

Rubins, H.B., Robins, S.J., Collins, D., Fye, C.L., Anderson, J.W., Elam, M.B., Faas, F.H., Linares, E., Schaefer, E.J., Schectman, G., et al. 1999. Gemfibrozil for the secondary prevention of coronary heart disease in men with low levels of high-density lipoprotein cholesterol. N. Engl. J. Med. 341: 410-418.

Sheng, Z., Otani, H., Brown, M.S., and Goldstein, J.L. 1995. Independent regulation of sterol regulatory element-binding proteins 1 and 2 in hamster liver. Proc. Natl. Acad. Sci. 92: 935-938.

Shimano, H., Horton, J.D., Hammer, R.E., Shimomura, I., Brown, M.S., and Goldstein, J.L. 1996. Overproduction of cholesterol and fatty acids causes massive liver enlargement in transgenic mice expressing truncated SREBP-1a. J. Clin. Investig. 98: 1575-1584.

Shimomura, I., Shimano, H., Korn, B.S., Bashmakov, Y., and Horton, J.D. 1998. Nuclear sterol regulatory element-binding proteins activate genes responsible for the entire program of unsaturated fatty acid biosynthesis in transgenic mouse liver. J. Biol. Chem. 273: 35299-35306.

Song, C., Kokontis, J.M., Hiipakka, R.A., and Liao, S. 1994. Ubiquitous receptor: A receptor that modulates gene activation by retinoic acid and thyroid hormone receptors. Proc. Natl. Acad. Sci. 91: 10809-10813.

Sullivan, A.K., Feher, M.D., Nelson, M.R., and Gazzard, B.G. 1998. Marked hypertriglyceridaemia associated with ritonavir therapy. AIDS 12: 1393-1394.

Venkateswaran, A., Repa, J.J., Lobaccaro, J.M., Bronson, A., Mangelsdorf, D.J., and Edwards, P.A. 2000. Human white/ murine ABC8 mRNA levels are highly induced in lipidloaded macrophages: A transcriptional role for specific oxysterols. J. Biol. Chem. 275: 14700-14707.

Willy, P.J., Umesono, K., Ong, E.S., Evans, R.M., Heyman, R.A, and Mangelsdorf, D.J. 1995. LXR, a nuclear receptor that defines a distinct retinoid response pathway. Genes \& Dev. 9: 1033-1045.

Yokode, M., Hammer, R.E., Ishibashi, S., Brown, M.S., and Goldstein, J.L. 1990. Diet-induced hypercholesterolemia in mice: Prevention by overexpression of LDL receptors. Science 250: 1273-1275. 


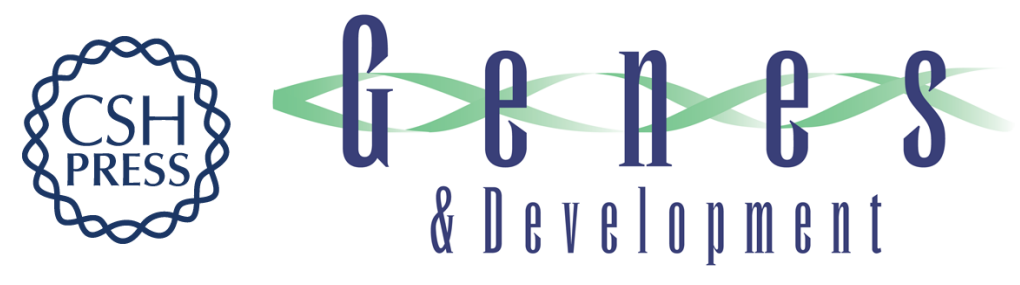

\section{Role of LXRs in control of lipogenesis}

Joshua R. Schultz, Hua Tu, Alvin Luk, et al.

Genes Dev. 2000, 14:

Access the most recent version at doi:10.1101/gad.850400

References This article cites 34 articles, 18 of which can be accessed free at: http://genesdev.cshlp.org/content/14/22/2831.full.html\#ref-list-1

License

Email Alerting Receive free email alerts when new articles cite this article - sign up in the box at the top Service right corner of the article or click here.

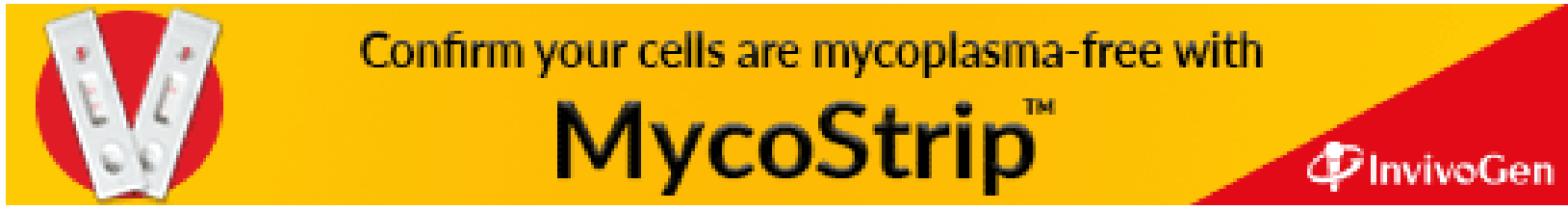

